\title{
Prevalence and aetiology of moderate and severe thrombocytopenia in a tertiary and quaternary centre in KwaZulu-Natal
}

\begin{tabular}{|c|c|}
\hline \multicolumn{2}{|c|}{$\begin{array}{l}\text { Authors: } \\
\text { Ayanda G.P. Jali i, } \\
\text { Bongani B. Nkambule }\end{array}$} \\
\hline \multicolumn{2}{|c|}{$\begin{array}{l}\text { Affiliations: } \\
\text { 'Department of Haematology, } \\
\text { Health King Edward VIII } \\
\text { Hospital, University of } \\
\text { Kwa-Zulu Natal, Durban, } \\
\text { South Africa }\end{array}$} \\
\hline \multicolumn{2}{|c|}{$\begin{array}{l}{ }^{2} \text { Department of Haematology, } \\
\text { National Health Laboratory } \\
\text { service, Inkosi Albert Luthuli } \\
\text { Academic Hospital, Durban, } \\
\text { South Africa }\end{array}$} \\
\hline \multicolumn{2}{|c|}{$\begin{array}{l}{ }^{3} \text { Department of Human } \\
\text { Physiology, School of } \\
\text { Laboratory Medicine and } \\
\text { Medical Sciences, University } \\
\text { of KwaZulu-Natal, Durban, } \\
\text { South Africa }\end{array}$} \\
\hline \multicolumn{2}{|c|}{$\begin{array}{l}\text { Corresponding author: } \\
\text { Ayanda Jali, } \\
\text { juhjali@gmail.com }\end{array}$} \\
\hline \multicolumn{2}{|c|}{$\begin{array}{l}\text { Received: } 12 \text { Mar. } 2018 \\
\text { Accepted: } 02 \text { June } 2020 \\
\text { Published: } 24 \text { Aug. } 2020\end{array}$} \\
\hline \multicolumn{2}{|c|}{$\begin{array}{l}\text { How to cite this article: } \\
\text { Jali AGP, Nkambule BB. } \\
\text { Prevalence and aetiology } \\
\text { of moderate and severe } \\
\text { thrombocytopenia in a } \\
\text { tertiary and quaternary } \\
\text { centre in KwaZulu-Natal. } \\
\text { Afr J Lab Med. 2020;9(1), } \\
\text { a799. https://doi.org/ } \\
\text { 10.4102/ajlm.v9i1.799 }\end{array}$} \\
\hline \multicolumn{2}{|c|}{$\begin{array}{l}\text { Copyright: } \\
\text { ( 2020. The Authors. } \\
\text { Licensee: AOSIS. This w } \\
\text { is licensed under the } \\
\text { Creative Commons } \\
\text { Attribution License. }\end{array}$} \\
\hline \multirow[b]{2}{*}{ 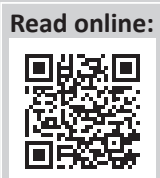 } & \\
\hline & $\begin{array}{l}\text { Scan this QR } \\
\text { code with your } \\
\text { smart phone or } \\
\text { mobile device } \\
\text { to read online. }\end{array}$ \\
\hline
\end{tabular}

Background: Thrombocytopenia is a common haematological disorder, characterised by platelet counts below $150 \times 10^{9} / \mathrm{L}$. The aetiology of thrombocytopenia is multifactorial; notably, in a misdiagnosis this condition may be due to pre-analytical laboratory artefacts. Knowledge about the common aetiology of thrombocytopenia will assist clinicians in decision-making and interpretation of laboratory tests and this may lead to prompt, adequate patient management and cost-saving measures.

Objective: This study determined the prevalence and aetiology of moderate and severe thrombocytopenia in a tertiary or quaternary laboratory in Durban, KwaZulu-Natal, South Africa.

Methods: We conducted a retrospective study at the Inkosi Albert Luthuli Central Hospital haematology laboratory between October 2015 and April 2016. A total of 2076 full blood count results with a platelet count of less than $100 \times 10^{9} / \mathrm{L}$ were retrieved from the Inkosi Albert Luthuli Academic Hospital database. Laboratory data were extracted and matched with clinical data and used to identify the potential aetiology of thrombocytopenia.

Results: The prevalence of thrombocytopenia was $14.9 \%$ within the selected study period. The haematology or oncology wards and clinic accounted for 55.2\% of thrombocytopenia cases, whereas the adult and paediatric intensive care units accounted for $29.3 \%$. Notably, $15.5 \%$ of thrombocytopenia cases were reported in non-haematology wards and clinics. The most common cause of thrombocytopenia was chemotherapy which accounted for $38.5 \%$ of all causes.

Conclusion: In our tertiary and quaternary setting, thrombocytopenia in adults was most common in patients admitted to haematology and oncology wards. Moreover, chemotherapy-induced thrombocytopenia accounted for more than a third of all these cases.

Keywords: thrombocytopenia; prevalence; aetiology; South Africa; haematology.

\section{Introduction}

Thrombocytopenia is a common clinical condition that is associated with multiple systemic diseases. Thrombocytopenia is characterised by platelet counts below $150 \times 10^{9} / \mathrm{L}$. However, only platelet counts of less than $100 \times 10^{9} / \mathrm{L}$ are considered clinically significant. ${ }^{1}$ Moderate thrombocytopenia is defined as a platelet count range of 50-100 $\times 10^{9} / \mathrm{L}$, while severe thrombocytopenia is classified by a platelet count of less than $50 \times 10^{9} / \mathrm{L} .^{2}$ The aetiology of thrombocytopenia varies and may be caused by mild to life-threatening clinical conditions. However misdiagnosis of thrombocytopenia also occurs, and could be the result of artefactual laboratory errors. ${ }^{3,4} \mathrm{~A}$ full blood count and peripheral blood smear are mandatory as an initial test in patients with thrombocytopenia. ${ }^{1,5}$ Although there have been advances in the automation of haematology analysers, the peripheral blood smear still remains an important diagnostic tool. ${ }^{1}$ It provides an informed interpretation of the full blood count results, as there are morphological abnormalities that an automated analyser cannot detect. ${ }^{3,6}$ In particular, it helps to distinguish between thrombocytopenia due to laboratory errors and true thrombocytopenia. ${ }^{3}$ Thrombocytopenia can be caused by decreased thrombopoiesis in the bone marrow and increased sequestration of platelets by the spleen as a result of malignancy, aplastic anaemia, myelodysplastic syndrome and opportunistic infections. ${ }^{1,7}$ Another aetiology of thrombocytopenia is increased peripheral destruction of platelets that may occur following disseminated intravascular coagulation, thrombotic microangiopathy and increased platelet sequestration due to hypersplenism..$^{4,8}$ 
For prompt and adequate management of patients with thrombocytopenia, a comprehensive review of the patients' medical records should be performed by the treating clinician, and appropriate physical examination and investigations need to be performed. ${ }^{1}$ Previous studies have shown an increased prevalence of thrombocytopenia in hospitalised patients in developing and developed countries. ${ }^{4,9,10}$ In patients with haematological malignancies receiving chemotherapy, thrombocytopenia as a consequence of drug toxicity levels has been reported. ${ }^{12}$ Understanding the aetiology of thrombocytopenia in hospitalised patients is pivotal, as thrombocytopenia may lead to complications in patients with a variety of conditions. ${ }^{9,10,11}$ In a previous study conducted in Johannesburg, South Africa in 2012, the authors reported on chemotherapy and sepsis as the common causes of thrombocytopenia, irrespective of HIV status. ${ }^{4}$ However, the prevalence and aetiology of thrombocytopenia in a tertiary or quaternary hospital setting remains unknown as data describing this remain scarce. The aim of this study was to determine the prevalence and clinical diagnosis associated with thrombocytopenia in patients presenting at Inkosi Albert Luthuli Central Hospital in KwaZulu-Natal between October 2015 and April 2016.

\section{Methods \\ Ethical considerations}

The study received ethical approval from the University of KwaZulu-Natal Biomedical Research and Ethics Committee (Approval number: BE 297/16).

\section{Sample selection and data extraction}

This retrospective study was conducted at the Department of Haematology at Inkosi Albert Luthuli Central Hospital (IALCH), Durban, KwaZulu-Natal, South Africa. The department offers diagnostic haematology services to the entire province of KwaZulu-Natal. The IALCH is an 846-bed referral hospital that provides tertiary level services to the entire KwaZulu-Natal province and parts of the Eastern Cape.

\section{Data collection}

Patients' diagnostic test results and clinical notes were retrieved from the IALCH TRAK laboratory data management system, version 6.10.56 (Intersystems Corporation, Cambridge, Massachusetts, United States). The extracted laboratory data items included the peripheral blood film report, diagnosis, platelet count, ward number and hospitalisation status. Clinical data items were retrieved from Meditech version 615 (Meditech, Westwood, Massachusetts, United States). The extracted patient information included age, sex, type of ward, hospitalisation status and the cause of thrombocytopenia in these patients.

A total of 2076 full blood count results were extracted from the TRAK database. These results were from samples received at IALCH haematology laboratory on non-consecutive weekdays from October 2015 to April 2016. This was in an effort to

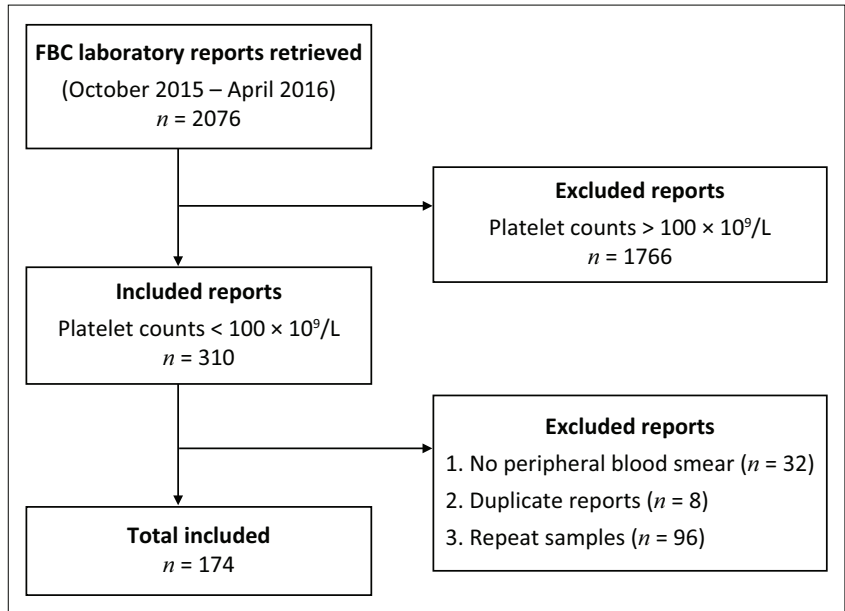

FBC, full blood count; $n$, number of reports.

FIGURE 1: Study design. This study included full blood count reports retrieved from the Department of Haematology for patients presenting at the Inkosi Albert Luthuli Central Hospital, Durban, KwaZulu-Natal, South Africa (October 2015 - April 2016).

minimise the inclusion of repeat samples in our analysis. All samples were analysed using the same Sysmex XE5000 analyser (Sysmex Corporation, Chuo-ku, Kobe, Japan). The study included patient reports that fulfilled the study inclusion criteria of a platelet count of $<100 \times 10^{9} / \mathrm{L}$ and had a corresponding peripheral blood smear report (Figure 1).

\section{Sample size determination}

In order to determine the prevalence of thrombocytopenia, we computed a minimum required sample size $(n)$ of 304 based on the thrombocytopenia prevalence of $20 \%$ and an appropriate precision (d) of 0.05 and a $95 \%$ confidence interval width of $15.5 \%-24.5 \% \cdot{ }^{13}$ Furthermore, a sub-sample size of 170 was required to estimate the aetiology of thrombocytopenia with a $5 \%$ probability of error and assuming that $50 \%$ of cases are due to acquired factors.

\section{Statistical analysis}

The Kolmogorov-Smirnov and Lilliefors tests for normality were used to assess data distribution. Parametric data such as platelet count and cluster of differentiation 4 T-cell counts were reported as mean and standard deviations. Platelet counts were ordered into two categories (i.e. $<50$ and 51-100). The Fisher's exact test was used for comparisons between ordinal data (age, platelet count, diagnosis and race). The prevalence of thrombocytopenia was reported as a proportion of patients with the disease. Furthermore, associations between patient characteristics (age, sex and hospital ward) and aetiology of thrombocytopenia were assessed. A $p$-value of $<0.05$ was regarded as statistically significant. All data analyses were performed using the Stata version 13.1 statistical software (StataCorp LP, College Station, Texas, United States).

\section{Results}

A total of 2076 full blood count reports were retrieved from the IALCH database. Among these, 174 reports that met 
the inclusion criteria were included in the study (Figure 1). The extracted participant data included age, gender, peripheral blood film report, diagnosis, platelet count, ward number and hospitalisation status.

\section{Patient characteristics}

The study comprised 174 thrombocytopenia patients with a mean age of $24.4 \pm 2.9$ years. This consisted of patients receiving both inpatient and outpatient care (Table 1). The HIV status of

TABLE 1: Characteristics of patients presenting at the Department of Haematology Inkosi Albert Luthuli Central Hospital, Durban, KwaZulu-Natal, South Africa (October 2015 - April 2016).

\begin{tabular}{lcc}
\hline Variable & $n$ & $\%$ \\
\hline Age & 65 & 37.4 \\
$0-12$ & 38 & 21.8 \\
$13-24$ & 26 & 14.9 \\
$25-36$ & 17 & 9.8 \\
$37-48$ & 17 & 9.8 \\
$49-60$ & 11 & 6.3 \\
$>60$ & & \\
Sex & 85 & 48.9 \\
$\quad$ Male & 89 & 51.1 \\
$\quad$ Female & 49.9 & 30.5 \\
Platelet count (mean, SD) & & \\
HIV status & 31 & 17.8 \\
Positive & 115 & 66.1 \\
Negative & 28 & 16.1 \\
$\quad$ Not determined $\dagger$ & 261.3 & 199.3 \\
CD4 count (cells/ $\mu$ L mean, SD) $\dagger$ & & \\
Hospitalisation status & 149 & 14.4 \\
Inpatient & 25 & \\
Outpatient & & \\
\hline
\end{tabular}

$n=174$.

CD4, cluster of differentiation 4

$\dagger$, No laboratory results available.

$\$$, CD4 counts of all HIV-positive patients. the thrombocytopenia patients was reported in $146(83.9 \%)$ of the included cases, while it was not determined in $28(16.1 \%)$ (Table 1). Thirty-one $(21.2 \%)$ of the thrombocytopenia patients were HIV-positive with a mean cluster of differentiation 4 T-cell count of $261.3 \pm 199.3$ cells $/ \mu \mathrm{L}$.

\section{Prevalence and aetiology of moderate to severe thrombocytopenia}

The overall prevalence of thrombocytopenia was $14.9 \%$. The paediatric population (0-12 years) had the highest prevalence of thrombocytopenia (37.4\%) compared with those aged 13-24 years (21.8\%), 25-36 years (14.9\%), 37-48 years $(9.8 \%), 49-60$ years $(9.8 \%)$ and $>60$ years $(6.3 \%)$ (Table 1). In the overall cohort, the prevalence of thrombocytopenia was higher in female patients $(51.1 \%)$ compared to male patients $(48.9 \%), p<0.001$. Thrombocytopenia was most common in inpatients $(85.6 \%)$ compared to outpatients $(14.4 \%), p<0.001$. The adult and paediatric haematology and oncology wards and clinic had the highest prevalence of thrombocytopenia (55\%), whereas the adult and paediatric intensive care units (29.3\%) and the non-haematology wards and clinic (15.5\%) had a lower prevalence, $p<0.001$. Overall, severe thrombocytopenia (platelet count $\leq 50 \times 10^{9} / \mathrm{L}$ ) was twofold higher $(64.9 \%)$ than moderate thrombocytopenia (35.1\%), $p=0.004$ (Table 2).

Chemotherapy-induced thrombocytopenia (38.5\%) and sepsis (27.6\%) accounted for the majority of thrombocytopenia cases (Table 2). Malignancies accounted for $11.5 \%$, immune thrombocytopenic purpura $4.6 \%$ and aplastic anaemia $4.6 \%$. Aetiologies with a prevalence less than $4 \%$ were grouped into one category and these comprised trauma as well as pre-eclampsia, storage disorders, autoimmune disorders, hereditary thrombocytopenia and human leukocyte antigen

TABLE 2: Aetiology of thrombocytopenia in patients presenting at the Department of Haematology Inkosi Albert Luthuli Central Hospital, Durban, KwaZulu-Natal, South Africa (October 2015 - April 2016).

\begin{tabular}{|c|c|c|c|c|c|c|c|c|c|c|c|c|c|c|c|}
\hline \multirow[t]{2}{*}{ Parameter } & \multicolumn{2}{|c|}{ Malignancies } & \multicolumn{2}{|c|}{ Sepsis } & \multicolumn{2}{|c|}{ Chemo } & \multicolumn{2}{|c|}{ Pregnancy } & \multicolumn{2}{|c|}{ ITP } & \multicolumn{2}{|c|}{ Aplastic } & \multicolumn{2}{|c|}{ Other } & \multirow[t]{2}{*}{$p$-value } \\
\hline & $n$ & $\%$ & $n$ & $\%$ & $n$ & $\%$ & $n$ & $\%$ & $n$ & $\%$ & $n$ & $\%$ & $n$ & $\%$ & \\
\hline \multicolumn{16}{|l|}{ Sex } \\
\hline Male & 8 & 4.6 & 19 & 10.9 & 42 & 24.1 & - & - & 1 & 0.6 & 7 & 4.0 & 4.0 & 2.3 & $<0.001$ \\
\hline Female & 12 & 6.9 & 29 & 16.7 & 25 & 14.4 & 9 & 5.2 & 7 & 4.0 & 1 & 0.6 & 14 & 8.0 & \\
\hline \multicolumn{16}{|l|}{ Age group } \\
\hline 0-12 years & 6 & 3.4 & 35 & 20.1 & 14 & 8.0 & 0 & - & 0 & - & 3 & 1.7 & 7 & 4.0 & ND \\
\hline $13-24$ years & 6 & 3.4 & 1 & 0.6 & 18 & 10.3 & 5 & 2.9 & 5 & 2.9 & 2 & 1.1 & 5 & 2.9 & \\
\hline $25-36$ years & 4 & 2.3 & 5 & 2.9 & 8 & 4.6 & 4 & 2.3 & 2 & 1.1 & 2 & 1.1 & 3 & 1.7 & \\
\hline $37-48$ years & 1 & 0.6 & 3 & 1.7 & 11 & 6.3 & 0 & - & 0 & - & 0 & - & 1 & 0.6 & \\
\hline $49-60$ & 1 & 0.6 & 3 & 1.7 & 10 & 5.7 & 0 & - & 1 & 0.6 & 1 & 0.6 & 1 & 0.6 & \\
\hline$>60$ & 2 & 1.1 & 1 & 0.6 & 6 & 3.4 & 0 & - & 0 & - & 0 & - & 1 & 0.6 & \\
\hline \multicolumn{16}{|l|}{ Platelet count } \\
\hline$\leq 50$ & 15 & 8.6 & 35 & 20.1 & 41 & 23.6 & 4 & 2.3 & 3 & 1.7 & 8 & 4.6 & 11 & 6.3 & 0.075 \\
\hline 51-100 & 5 & 2.9 & 13 & 7.5 & 26 & 14.9 & 5 & 2.9 & 5 & 2.9 & 0 & - & 7 & 4.0 & \\
\hline \multicolumn{16}{|l|}{ Patient } \\
\hline Inpatient & 17 & 9.8 & 48 & 27.6 & 57 & 32.8 & 9 & 5.2 & 7 & 4.0 & 0 & - & 15 & 8.6 & $<0.001$ \\
\hline Outpatient & 3 & 1.7 & 0 & - & 10 & 5.7 & 0 & - & 1 & 0.6 & 8 & 4.6 & 3 & 1.7 & \\
\hline Medical & 20 & 11.5 & 44 & 25.3 & 67 & 38.5 & 5 & 2.9 & 8 & 4.6 & 8 & 4.6 & 15 & 8.6 & $<0.001$ \\
\hline Surgical & 0 & - & 4 & 2.3 & 0 & - & 4 & 2.3 & 0 & - & 0 & - & 3 & 1.7 & \\
\hline Total & 20 & 11.5 & 48 & 27.6 & 67 & 38.5 & 9 & 5.2 & 8 & 4.6 & 8 & 4.6 & 18 & 10.3 & \\
\hline
\end{tabular}

ND, not determined due to low subgroup numbers.

Statistically significant results $(p<0.05)$ are shown in bold.

Chemo, chemotherapy; ITP, immune thrombocytopenic purpura; Aplastic, Aplastic anaemia. 
antibodies to platelets, which accounted for between 0.6 and $1.7 \%$.

\section{Discussion}

In this study, we report a thrombocytopenia prevalence of $14.9 \%$, which is higher than the $8.6 \%$ prevalence reported in a similar study conducted at an academic state hospital in Johannesburg, South Africa. ${ }^{4}$ This higher prevalence may be due to the fact that the current study was conducted at a tertiary and quaternary hospital, to which only specific cases are referred and this could result in an overestimation of the prevalence of thrombocytopenia. In addition, other studies have reported on seasonal and genetic variations in platelet counts. ${ }^{14}$ Taken together these factors may account for the differences in the prevalence of thrombocytopenia. In fact, seasonal variations in platelet counts have been reported with lower platelet counts observed in spring and summer, while slightly elevated platelet counts have been observed in autumn and winter. ${ }^{14,15}$ Notably our study period fell within a low thrombocytopenia season (summer and autumn); this may suggest that the reported platelet counts in patients with severe thrombocytopenia were not influenced by seasonal variations but may have led to an underestimation of thrombocytopenia in our setting. Notably, only $17.8 \%$ of the patients included in our study were HIV-positive compared to $36 \%$ reported in the previous retrospective study by Vaughan et al. reporting on patient full blood count reports authorised in 2012, at the Chris Hani Baragwanath Academic Hospital, South Africa. ${ }^{4}$ We further report on a higher frequency of thrombocytopenia in hospitalised patients compared to outpatients, which is similar to that previously described. ${ }^{4}$ This may be due to the differences in diagnosis and disease severity between admitted patients and outpatients. Moreover, in our study thrombocytopenia was particularly common among patients admitted to haematology and oncology wards, intensive care units, neonatal intensive care units and medical wards, while a minority of thrombocytopenia cases $(1.7 \%)$ were from non-haematology clinics. These findings are consistent with those previously reported. Interestingly, in our study thrombocytopenia was common particularly among children below the age of 12 years and the majority of the cases were due to sepsis.

More than a third of cases referred to the haematology department with thrombocytopenia were classified as chemotherapy-induced. The mechanism of thrombocytopenia in chemotherapy-induced thrombocytopenia involves reduced platelet production, an increased rate of platelet destruction and enhanced platelet clearance by immune mechanisms. ${ }^{7}$ Bone marrow infiltration by malignancy can cause suppression of megakaryopoiesis, resulting in thrombocytopenia. ${ }^{1,7}$ In our study, malignancies accounted for more thrombocytopenia cases when compared to bone marrow failure. Contrary to our findings, a study conducted in Johannesburg, South Africa in 2012 showed that bone marrow failure accounted for $9.6 \%$ of cases while malignancies accounted for $7.4 \%$ of thrombocytopenia cases. ${ }^{4}$
Thrombocytopenia due to sepsis accounted for $27.6 \%$ of the cases, a majority of which were in the intensive care unit. The majority of cases presenting with sepsis had severe thrombocytopenia; these findings were similar to those previously described. ${ }^{16}$ Studies have shown that the prevalence of thrombocytopenia in sepsis ranges from $33.8 \%$ to $60 \% .5,6,17$ Immune thrombocytopenic purpura, an isolated thrombocytopenia with no associated clinical conditions, ${ }^{18}$ was seen in $4.6 \%$ of the participants and most participants were between 13 and 24 years; the majority were in the obstetrics and labour ward $(87.5 \%)$. In adults, immune thrombocytopenic purpura is a chronic disease resulting from an autoimmune disorder mediated by platelet antibodies, increased platelet destruction and impaired platelet production. ${ }^{18,19}$

Contrary to literature, immune thrombocytopenic purpura was not common among the paediatric group (12.5\%). ${ }^{19}$ Neonatal thrombocytopenia commonly occurs as a result of increased platelet destruction or sequestration resulting from infections, respiratory distress syndrome or infants whose mothers had pre-eclampsia. ${ }^{20}$ Thrombocytopenia can also be the result of decreased platelet production in congenital abnormalities of the newborn such as thrombocytopenia absent radii. ${ }^{20}$ Thrombocytopenia can also be seen in children who are well and commonly as an isolated thrombocytopenia resulting from immune causes such as in infants born to mothers with immune thrombocytopenic purpura and in those with neonatal alloimmune thrombocytopenia.

In our study, the prevalence of pregnancy-associated thrombocytopenia was $5.2 \%$, which is lower in comparison to other studies. ${ }^{8,9,21}$ Pregnancy-associated thrombocytopenia occurs in $6 \%-10 \%$ of pregnant patients; however, its prevalence depends on its association with other medical conditions..$^{22}$ The diagnosis of gestational thrombocytopenia is a diagnosis of exclusion and accounts for the majority of all cases of thrombocytopenia during pregnancy. ${ }^{23,24}$

\section{Limitations}

Care should be taken in generalising the findings of the study because of the small numbers included in the study. The patient characteristics of those included may also differ from those seen at other levels of the healthcare system. Other limitations encountered were a lack of family history and other medications patients were taking, as this would have allowed for the classification and consideration of familial and drug-induced thrombocytopenia.

\section{Conclusion}

In our study, thrombocytopenia was common in hospitalised patients compared to outpatients. Chemotherapy, sepsis and malignancies were the most common causes of thrombocytopenia. Focused investigations are warranted for prompt patient management. Knowledge of the prevalence and common aetiology of thrombocytopenia in a healthcare facility will assist clinicians in decision-making 
and interpretation of laboratory test results, leading to prompt and adequate patient management and potentially offsetting patient costs that may be incurred due to unwarranted laboratory investigations. Further research in this field is required at different levels of healthcare as differences in the reported prevalence of thrombocytopenia may be the result of differences in patient demographics and clinical presentation of patients, which may differ between these facilities.

\section{Acknowledgements}

The authors would like to thank the Department of Haematology, National Health Laboratory Service laboratory, Inkosi Albert Luthuli Central Hospital and Inkosi Albert Luthuli Central Hospital for granting access to the patient database.

\section{Competing interests}

The authors declare that there are no financial, personal or professional competing interests that may interfere with this work.

\section{Authors' contributions}

A.G.P.J. performed the experiments, designed the study and wrote the paper; B.B.N. contributed to the revision of the intellectual content. All authors gave their approval of the final version to be submitted for publication.

\section{Sources of support}

B.B.N. is a University of KwaZulu-Natal Developing Research Innovation, Localisation and Leadership in South Africa fellow. Developing Research Innovation, Localisation and Leadership in South Africa is a United States National Institutes of Health D43 grant (D43TW010131) awarded to the University of KwaZulu-Natal in 2015 to support a research training and induction programme for early-career academics.

\section{Data availability statement}

Data sharing is not applicable to this article as no new data were created or analysed in this study.

\section{Disclaimer}

The views and opinions expressed in this article are those of the authors and do not necessarily reflect the official policy or position of any affiliated agency of the authors.

\section{References}

1. Stasi R. How to approach thrombocytopenia. Hematology Am Soc Hemato Educ Program. 2012;2012(1):191-197. https://doi.org/10.1182/asheducation2012.1.191

2. Gernsheimer T, James $A H$, Stasi R. How I treat thrombocytopenia in pregnancy. Blood. 2013;121(1):38-47. https://doi.org/10.1182/blood-2012-08-448944

3. Zhang L, Xu J, Gao L, Pan S. Spurious thrombocytopenia in automated platelet count. Lab Med. 2018;49(2):130-133. https://doi.org/10.1093/labmed/Imx081

4. Vaughan JL, Fourie J, Naidoo S, Subramony N, Wiggill T, Alli N. Prevalence and causes of thrombocytopenia in an academic state sector laboratory in Soweto, Johannesburg, South Africa. S Afr Med J. 2015;105(3):215-219. https://doi.org/10.7196/samj.8791

5. Provan D, Stasi R, Newland AC, et al. International consensus report on the investigation and management of primary immune thrombocytopenia. Blood. 2010;115(2):168-186. https://doi.org/10.1182/blood-2009-06-225565

6. Bain BJ. Diagnosis from the blood smear. N Engl J Med. 2005;353(5):498-507. https://doi.org/10.1056/NEJMra043442

7. Zeuner A, Signore M, Martinetti D, Bartucci $M$, Peschle C, De Maria R. Chemotherapy-induced thrombocytopenia derives from the selective death of megakaryocyte progenitors and can be rescued by stem cell factor. Cancer Res. 2007;67(10):4767-4773. https://doi.org/10.1158/0008-5472.CAN-06-4303

8. Williamson DR, Albert M, Heels-Ansdell D, et al. Thrombocytopenia in critically il patients receiving thromboprophylaxis: Frequency, risk factors, and outcomes. Chest. 2013;144(4):1207-1215. https://doi.org/10.1378/chest.13-0121

9. Teo CP, Kueh YK. Incidence of thrombocytopenia in an acute care hospital. Ann Acad Med Singapore. 1989;18(4):379-381.

10. Fountain EM, Arepally GM. Etiology and complications of thrombocytopenia in hospitalized medical patients. J Thromb Thrombolysis. 2017;43(4):429-436. https://doi.org/10.1007/s11239-016-1467-8

11. ChaturvediS, Kohli R, McCrae K. Over-testing for heparin induced thrombocytopenia in hospitalized patients. J Thromb Thrombolysis. 2015;40(1):12-16. https://doi.org/ 10.1007/s11239-014-1123-0

12. Soff GA, Shaw J, Kilpatrick K, Marongiu A, Park J. Burden of thrombocytopenia in adult cancer patients receiving chemotherapy. J Clin Oncol. 2019;37(15):1555-1555. https://ascopubs.org/doi/abs/10.1200/JCO.2019.37.15_suppl.1555

13. Louie KS, Micallef JM, Pimenta JM, Forssen UM. Prevalence of thrombocytopenia among patients with chronic hepatitis C: A systematic review. J Viral Hepat. 2011;18(1):1-7. https://doi.org/10.1111/j.1365-2893.2010.01366.x

14. Buckley MF, James JW, Brown DE, et al. A novel approach to the assessment of variations in the human platelet count. Thromb Haemost. 2000;83(03):480-484. https://doi.org/10.1055/s-0037-1613840

15. Liu B, Taioli E. Seasonal variations of complete blood count and inflammatory biomarkers in the US population-analysis of NHANES data. PLoS One. 2015;10(11):e0142382. https://doi.org/10.1371/journal.pone.0142382

16. Venkata C, Kashyap R, Farmer JC, Afessa B. Thrombocytopenia in adult patients with sepsis: Incidence, risk factors, and its association with clinical outcome. J Intensive Care. 2013;1(1):9. https://doi.org/10.1186/2052-0492-1-9

17. Boechat Tde O, Silveira MF, Faviere W, Macedo GL. Thrombocitopenia in sepsis: An important prognosis factor. Rev Bras Ter intensiva. 2012;24(1):35-42.

18. Thota S, Kistangari G, Daw H, Spiro T. Immune thrombocytopenia in adults: An update. Cleve Clin J Med. 2012;79(9):641-650. https://doi.org/10.3949/ccjm.79a.11027

19. Grimaldi-Bensouda L, Nordon C, Michel M, et al. Immune thrombocytopenia in adults: A prospective cohort study of clinical features and predictors of outcome. Haematologica. 2016;101(9):1039-1045. https://doi.org/10.3324/ haematol.2016.146373

20. Arora M, Goyal L, Khutan H. Prevalence of thrombocytopenia during pregnancy and its effect on pregnancy and neonatal outcome. Ann Int Med Dent Res. 2019;3(2):4. https://doi.org/10.4103/ijh.ijh_17_18

21. Sebitloane HM. Thrombocytopenia during pregnancy in women with HIV infection receiving no treatment. S Afr Med J. 2016;106(2):210-213. https://doi.org/ 10.7196/SAMJ.2016.v106i2.9903

22. Dwivedi P, Puri M, Nigam A, Agarwal K. Fetomaternal outcome in pregnancy with severe thrombocytopenia. Eur Rev Med Pharmacol Sci. 2012;16(11):1563-1566.

23. McCrae KR. Thrombocytopenia in pregnancy: Differential diagnosis, pathogenesis, and management. Blood Rev. 2003;17(1):7-14. https://doi.org/10.1016/s0268960x(02)00056-5

24. Ciobanu AM, Colibaba S, Cimpoca B, Peltecu G, Panaitescu AM. Thrombocytopenia in pregnancy. Maedica (Buchar). 2016;11(1):55. 